\title{
AVALIAÇÃO EXTERNA E ESCOLAS CHARTERS: MONITORAMENTO E INDUÇÃO DAS POLÍTICAS EDUCACIONAIS
}

http://dx.doi.org/10.5902/2318133826509

\author{
Henrique Dias Gomes de Nazareth \\ Universidade Federal do Estado do Rio de Janeiro, Brasil.
}

\begin{abstract}
Resumo
Neste artigo pretende-se discutir a inserção das políticas de avaliação em larga escala na defesa de modelos mercadológicos de educação pública, em especial no projeto proposto pelo governo de Goiás, inspirado nas escolas charters. Por meio de análise de documentos, revisão bibliográfica e publicações em jornais, revistas e sítios oficiais de redes de ensino, objetiva-se compreender o papel da avaliação em larga escala nesse contexto. Parte-se do pressuposto de que as políticas de avaliação externa têm sido essenciais para induzir a formulação de políticas educacionais baseadas na performatividade, meritocracia e privatização. Tudo isso acentua as desigualdades e favorece a criação de formas de exclusão e maneiras de burlar os resultados. Palavras-chave: avaliação externa, privatização, escolas charters, performatividade.
\end{abstract}

\section{EXTERNAL EVALUATION AND CHARTER SCHOOLS: MONITORING AND INDUCTION OF EDUCATIONAL POLICIES}

\begin{abstract}
This article intends to discuss the insertion of large-scale evaluation policies in the defense of marketing models of public education, especially in the project proposed by the government of Goiás inspired by charter schools. Through document analysis, bibliographic review and publications in newspapers, magazines and official sites of educational networks, the objective is to understand the role of evaluation on a large scale in this context. It is assumed that the policies of external evaluation have been essential to induce the formulation of education policies based on performativity, meritocracy and privatization. All this accentuates inequalities and favors the creation of forms of exclusion and ways of circumventing the results.

Key-words: external evaluation, privatization, charter schools, performativity.
\end{abstract}




\section{Introdução}

$\mathrm{N}$ as últimas duas décadas a educação pública brasileira passou por um momento de intensificação da lógica mercadológica. Isso significa dizer que estão ocorrendo mudanças no papel do Estado no que se refere à relação público-privado. As críticas à educação são acompanhadas por defesas de políticas que sustentam soluções fundadas em conceitos neoliberais.

Para compreender o papel que a avaliação externa tem desempenhado nesse contexto macro político, é preciso entendê-la como parte importante do projeto de educação neoliberal que demanda o estabelecimento de uma cultura de auditoria (Apple, 2005) e performatividade (Ball, 2005) para produzir evidências que apontem para a necessidade de intensificar a lógica do mercado na educação.

Neste artigo pretende-se discutir a inserção das políticas de avaliação em larga escala na defesa de modelos mercadológicos de educação pública, em especial no projeto de gestão compartilhada proposto pelo governo de Goiás inspirado nas escolas charters dos EUA.

O modelo conhecido como charters se caracteriza como escolas públicas geridas por instituições privadas, geralmente sem fins lucrativos. São entendidas como "escolas públicas que operam com liberdade superior a muitos dos regulamentos locais e estaduais que se aplicam a escolas públicas tradicionais" (Adrião, 2014, p. 274).

As escolas organizadas dessa forma podem exercer maior autonomia de gestão e contratação, no entanto, estas têm sido atreladas a uma maior responsabilização pelos resultados acadêmicos:

São escolas públicas, pois gratuitas, mas gozam de independência frente às normativas curriculares e às exigências trabalhistas ditadas pelos distritos às escolas públicas "tradicionais". Os graus de independência são variáveis e as equipes gestoras ou proprietária dessas escolas podem ser fortemente responsabilizadas (em alguns casos tendo suas licenças para funcionamento caçadas) quando o desempenho previsto e/ou as metas determinadas pelo distrito deixam de ser cumpridas. Estas escolas estão abertas a todas as crianças e a seleção de seus alunos dá-se geralmente por sorteio. (Adrião, 2014, p. 271)

Os modelos de escolas charters variam de acordo com as legislações e contextos locais, no entanto, três características comuns podem ser apontadas: em geral essas escolas recebem financiamento público de acordo com o número de matrículas e são gerenciadas, totalmente ou em parte, por uma instituição privada; são instituições que gozam de mais autonomia para selecionar e reter gestores e professores e os estudantes são admitidos por meio de sorteio ou critérios geográficos (Dias, 2010):

São escolas privadas subsidiadas por fundos públicos ou escolas públicas geridas por instituições privadas; as condições exigidas para que tais escolas sejam charters é que não haja cobrança de mensalidades ou matrículas, que operem segundo as normas estabelecidas pelos setores responsáveis e que possam ser escolhidas pelas famílias. (Adrião, 2014, p.278) 
O modelo de Goiás é tomado como exemplo para conduzir o debate, por sua publicidade e por apresentar um discurso de alternativa de qualidade e eficiência educacional. É uma das primeiras experiências de escola charter no Brasil ${ }^{1}$. No entanto, não se trata de um estudo de caso sobre o projeto. A experiência ainda é incipiente e no momento da escrita desse texto se encontra em fase de elaboração de um segundo edital de chamamento público, após a desclassificação de todas as organizações sociais que se inscreveram no primeiro.

Objetivando compreender o papel da avaliação em larga escala nesse contexto, parte-se do pressuposto de que as políticas de avaliação externa têm sido essenciais para a inserção da lógica neoliberal na educação. Os exames servem como a mola mestra que conduz as reformas educacionais.

\section{Neoliberalismo, privatização e performatividade}

Para Harvey (2008), o neoliberalismo é,

em primeiro lugar, uma teoria das práticas político-econômicas que propõe que o bem-estar humano pode ser melhor promovido liberando-se as liberdades e capacidades empreendedoras individuais no âmbito de uma estrutura institucional caracterizada por sólidos direitos a propriedade privada, livres mercados e livre comércio. (Harvey, 2008, p. 12)

Nesse sentido, o papel do Estado se modifica: "Enquanto o liberalismo clássico representa uma concepção negativa do poder do Estado, no sentido de que o indivíduo era tido como um objeto a ser libertado das suas intervenções" (Apple, 2005, p. 37), o neoliberalismo norteia o Estado a criar os mercados apropriados, inclusive em áreas sociais, e a fornecer condições que garantam o seu funcionamento:

O papel do Estado é criar e preservar uma estrutura institucional apropriada a essas práticas; o Estado tem de garantir, por exemplo, a qualidade e a integridade do dinheiro. Deve também estabelecer as estruturas e funções militares, de defesa, da política e legais requeridas para garantir direitos de propriedade individuais e para assegurar, se necessário pela força, o funcionamento apropriado dos mercados. Além disso, se não existirem mercados (em áreas como a terra, a água, a instrução, o cuidado de saúde, a segurança social ou a poluição ambiental), estes devem ser criados, se necessário pela ação do Estado. (Harvey, 2008, p.12)

De acordo com o autor, os defensores do neoliberalismo estão em posições de poder no campo da educação, nos meios de comunicação, nas instituições-chave do Estado, bem como nas agências multilaterais. Ou seja, aqueles que defendem os princípios neoliberais atuam no contexto de influência das políticas educacionais pela defesa de soluções de mercado para o que seriam problemas da educação. Esse contexto é "onde normalmente as políticas públicas são iniciadas e os discursos políticos são construídos. É nesse contexto que os grupos de interesse disputam para influenciar a definição das finalidades sociais da educação e do que significa ser educado" (Mainardes, 2006, p. 51).

1 A experiência pioneira de escolas charters no Brasil foi o Procentro, projeto de 2001 implantado em Pernambuco.

Regae: Rev. Gest. Aval. Educ. 
Além da esfera da formulação das políticas a doutrina possui capacidade de se inserir no senso comum, utilizando valores que são caros às sociedades, como a liberdade. Harvey (2008) alerta que ideais políticos, tais como dignidade humana e liberdade individual, foram incorporados como valores centrais das civilizações. Apple (2003) chama atenção para a questão e afirma que "um dos objetivos mais importantes da atuação direitista é mudar nosso senso comum, alterando o significado das categorias mais básicas, as palavras-chave que empregamos para compreender o mundo social e educacional e nosso lugar nele" (p. 11).

Assim, cria-se uma cultura de auditoria que busca envolver toda a sociedade. As políticas de avaliação externa estão atreladas aos meios de controle e supervisão, não somente pelo Estado, mas também pela sociedade em geral. A publicidade do ranqueamento das escolas, somada às provas elaboradas por agentes externos e a tentativa de padronização do currículo e material didático favorecem o monitoramento do conteúdo ensinado e do ritmo do ensino:

Em lugar de uma sociedade de cidadãos, com poder democrático para assegurar a eficiência e o uso correto dos recursos coletivos, e contando largamente com a confiança no setor público, surgiu uma sociedade de "auditores", que se preparam ansiosamente para auditorias e inspeções. Desenvolveu-se uma cultura punitiva de "tabelas de aferições" (league tables) - com a intenção de demonstrar a eficiência relativa e/ou a ineficiência de universidades, escolas e hospitais. (Leys apud Apple, 2005, p. 39)

Ball (2006) argumenta que passamos por uma profunda transformação na provisão pública dos serviços sociais, como educação e saúde. Logo, cria-se um ambiente moral baseado na competitividade e individualidade em lugar da solidariedade e coletividade. Ele ainda afirma que,

heuristicamente, essas mudanças devem ser situadas como parte de um processo mais amplo de transformação que Jessop descreve como a passagem do estado de bem-estar keynesiano (keynesiano welfare state kws) para um estado do trabalho schumpeteriano (sws - schumpeterian workfare state) (Jessop, 1994). De acordo com Jessop, essa transformação substituiu o discurso fordista de produtividade e planejamento por uma retórica de flexibilidade e empreendedorismo pósfordista. (Ball, 2006, p. 11)

Dentro da lógica da cultura de auditoria e considerando a capacidade de inserção desses valores no senso comum, Apple (2005) argumenta sobre a existência de um trabalho ideológico constante e sutil para a desvalorização dos serviços públicos e exaltação da iniciativa privada:

É preciso um trabalho ideológico criativo e de longo prazo e, ainda, as pessoas têm que ser forçadas a perceber que tudo que é público como "ruim" e o que é privado como "bom". E qualquer um que trabalhe nessas instituições públicas deve ser visto como ineficiente e necessitado da sensata realidade da competição, para que trabalhe mais horas arduamente (Apple, 2005, p. 41) 
As políticas de avaliação e meritocracia reforçam este propósito, elas introduzem a realidade da competição em detrimento da solidariedade. Existem pressões que, em última análise, podem desviar a função social da escola para o cumprimento de metas. Todavia, cabe sempre ressaltar que essas intenções transformam-se no contexto das práticas.

Sendo assim, instrumentos atrelados às políticas de avaliação externa como as provas em larga escala, os rankings, os índices e as premiações das escolas pelos resultados promovem a performatividade nas instituições escolares. Ball (2005) argumenta que

a performatividade é uma tecnologia, uma cultura e um método de regulamentação que emprega julgamentos, comparações e demonstrações como meios de controle, atrito e mudança. Os desempenhos de sujeitos individuais ou de organizações servem de parâmetros de produtividade ou de resultado, ou servem ainda como demonstrações de "qualidade" ou "momentos" de promoção ou inspeção. (p. 543)

Tais mudanças são acompanhadas por movimentos de privatização e depreciação do serviço público, pois, a estabilidade e direitos trabalhistas característicos do setor público são opostos aos valores prezados no contexto pós-fordista como competitividade e flexibilidade. Estes valores, de acordo com Ball (2011), fazem parte de um novo ambiente moral:

O que é alcançado com a introdução da forma de mercado na provisão pública não é meramente um novo mecanismo de alocação e distribuição de recursos, mas também a criação de um novo ambiente moral, tanto para consumidores quanto para produtores. Provedores públicos estão sendo introduzidos no que Plant (1992, p. 87) denomina uma "cultura dos interesses do self". O mercado celebra a ética do que Nagel (1991) denomina o "ponto de vista pessoal" - interesses pessoais e desejos individuais - e obscurece e deprecia o igualitarismo relacionado ao "ponto de vista impessoal". O que Nagel denomina "dualidade de pontos de vista", e vê como uma base para a ética prática e a estabilidade moral - isto é, o nexo entre eqüidade e parcialidade -, é então colapsado. Isso é parte do que Bottery denomina a "pauperização das concepções morais na esfera pública" (1992, p. 93). A ideia de deliberar e planejar almejando o "bem comum" torna-se sem sentido. (p.26)

Nessa lógica, a ideia de formação crítica, reflexiva e criativa torna-se inadequada. Os reformadores empresariais da educação (Freitas, 2011) privilegiam um aspecto cognitivo restrito do ser humano, visto que nem ao menos consideram as outras disciplinas constituídas na escola e focam, em alguns casos, somente em língua materna, matemática, e ciências.

Desta forma, é possível concordar com Freitas (2011) quando afirma que "estamos em um momento de inflexão na política pública da educação. A balança pende para a privatização, mediante novas formas de gestão e parcerias público-privadas nas quais se incluem contratos de gestão e os vouchers educacionais" (p. 87). 
Peroni e Caetano (2015) afirmam que suas pesquisas demonstraram que o processo de privatização no Brasil "ocorre de várias formas, tanto por meio da direção quanto da execução das políticas educativas" (p. 339). Nessa direção observam-se movimentos financiados por empresários que atuam na influência da agenda educacional. Atuam também na execução das propostas, oferecendo serviços de formação aos educadores, sistemas de avaliação, responsabilização e gestão.

\section{Escolas charters e gestão compartilhada}

No bojo dessa discussão, no final de 2015 e durante o ano de 2016, a rede estadual de educação de Goiás elaborou um projeto piloto que consiste em compartilhar a gestão de $25 \%$ de suas escolas com organizações sociais. Para questionamentos acerca do modelo de gestão compartilhada a Secretaria de Educação, Cultura e Esporte de Goiás Seduce - publicou em seu sítio oficial um documento denominado $O$ que você precisa saber sobre as OSs na educação. O documento é marcado pela intenção de demonstrar que o ensino permanecerá gratuito, sem a cobrança de taxas. Em vários pontos se ressalta que o modelo é diferente de privatização ou terceirização. De acordo com a Seduce (2016)

[organizações sociais] não é privatização. Privatizar é vender. Numa privatização há venda de patrimônio público e perda de controle para um agente privado obter lucro. No caso das Organizações Sociais, ocorre a gestão compartilhada das escolas, que permanecem públicas e gratuitas. A gestão do sistema permanece como uma atividade exclusiva e indelegável do Estado. O principal objetivo das OSs é tornar mais ágil a gestão das unidades, buscando a redução da burocracia e dos custos focando na melhoria da qualidade do ensino. (p. 1)

Divergindo do trecho supracitado, encontram-se pesquisas que apresentam concepções diferentes de privatização, que abarcam mecanismos mais complexos de transferência de recursos e responsabilidades. Ball (2013) disserta sobre os processos de privatização endógenos e exógenos: "Os primeiros tornando as organizações estatais mais eficientes e empresariais. Os segundos substituindo organizações estatais por fornecedores privados" (p. 178). Em outras palavras, a privatização não se refere apenas à venda de patrimônio público, é preciso considerar a introdução de mecanismos de gestão e controle provenientes do setor privado, além do repasse de recursos para essas organizações.

Lima e Gandin (2012) também argumentam que existem três formas de privatização. A primeira é a venda de bens públicos, a segunda ocorre por meio de parcerias públicoprivadas, que favorecem a implementação de "ideias do privado dentro do público" (p. 76), já a última se relaciona à transferência de responsabilidade do Estado para a sociedade civil.

Retornando ao caso de Goiás, pode-se enquadrar a proposta como privatização na segunda e terceira forma apontada. Indo além, percebe-se que o modelo se insere no que ficou conhecido nos Estados Unidos da América como escolas charters. Ou seja, escolas públicas com a gestão cedida à iniciativa privada. 
A filiação do projeto de Goiás ao modelo dos EUA é evidente, na medida em que, durante a sua elaboração, o governo goiano recebeu especialistas provenientes daquele país. O sítio oficial da Seduce retrata a visita dos pesquisadores norte-americanos Martin Carnoy e David N. Plank, da Universidade de Stanford, na Califórnia e vinculados ao Centro Lemann:

Carnoy frisou que um dos caminhos para melhorar o ensino público é replicar experiências bem sucedidas dentro e fora do Brasil. Segundo ele, nos Estados Unidos, por exemplo, há bons exemplos de escolas administradas por organizações sociais, modelo que se tornou conhecido como Charter Schools. (Seduce, 2016, p. 1)

Apesar dessa afirmação, o pesquisador americano Dwight Holmes, em entrevista concedida à professora Nora Krawczyk, da Unicamp, aponta algumas consequências negativas das experiências das escolas charters naquele país. Entre elas está o fechamento das escolas tradicionais de bairro com estudantes e verbas deslocadas para as novas escolas, denúncias de segregação de estudantes com desempenho considerado inadequado e instabilidade das instituições, pois "dados de 2000-2012, os últimos disponíveis, mostram o fechamento de $27 \%$ das escolas charter nesse período" (Holmes, 2016, p. ??-??).

Para os professores muitos aspectos também mudam. Com menos autonomia o trabalho docente é cada vez mais orientado para os testes de larga escala, além de ter volume de trabalho superior e salário médio inferior aos aplicados nas outras escolas. Não se sugere aqui que o modelo será importado denotativamente. As políticas educacionais são recontextualizadas em cada nação. Apesar de muitos aspectos comuns, elas estão imersas em questões culturais e históricas de cada país e região. Mesmo dentro do Brasil é possível observar muitas diferenças nas formas como estados e municípios escrevem o texto das políticas. Sobre o assunto, Akkari (2011) entende que,

no entanto, esses fluxos não são assimilados da mesma maneira pelas políticas nacionais de Educação. Esta assimilação vai depender da história da política educacional no país em questão e de outros fatores relacionados à política nacional. [...] O processo de internacionalização produz tensões nas políticas nacionais de Educação, tornando difícil a articulação entre as exigências nacionais (regionais e locais) e os imperativos internacionais (globais). (p.15)

Por isso, Ball (2001) define a criação de políticas nacionais como um processo de bricolagem: "Um constante processo de empréstimo e cópia de fragmentos e partes de ideias de outros contextos, de uso e melhoria das abordagens locais já tentadas e testadas, de teorias canibalizadoras, de investigação, de adoção de tendências e modas e, por vezes, de investimento em tudo aquilo que possa vir a funcionar (p. 102).

A proposta de gestão compartilhada de Goiás inclui a permanência do diretor eleito e a separação da gestão pedagógica e administrativa da escola. Nesse caso, o diretor deve servir como interlocutor da secretaria na unidade escolar. Pode-se problematizar essa distinção das duas esferas de gestão na medida em que o contrato de gestão deve prever metas de cunho pedagógico relacionadas ao desempenho e aprovação escolar. 
$\mathrm{Na}$ experiência americana, já citada, a autonomia docente é reduzida nas escolas charters e em muitas instituições os professores "são obrigados a usar apostilhas, produzidas de forma centralizadas para todo o país" (Holmes, 2016. p. 2). Há grande pressão para que o trabalho pedagógico seja orientado pelos testes, pois as escolas sofrem sanções e podem ser fechadas em alguns casos.

A relação trabalhista dos docentes das escolas do projeto goiano também é alvo de críticas. Obviamente não seria possível submeter servidores públicos estatutários à outra regulação trabalhista, mas o projeto pretende fortalecer e concentrar a contratação de professores celetistas:

Os [professores] efetivos continuam efetivos, podendo solicitar a transferência de unidade caso não se sintam à vontade para lecionar em uma escola gerida por OS. Os temporários e outros professores que queiram se candidatar farão um processo seletivo e, depois de aprovados, serão contratados pela OS e regidos pela Consolidação de Leis Trabalhistas (CLT), com todos os direitos trabalhistas. As OSs da Educação representarão também novas possibilidades de carreira para os profissionais da área, que poderão atuar em ótimas condições de trabalho; seleção, progressão e remuneração em bases estritamente meritocráticas e aplicação dos princípios da gestão democrática do ensino. (Holmes, 2016. p. 3)

Aqui se encontra o papel da avaliação externa nesse contexto, já que as bases meritocráticas se referenciam nos resultados dos exames. Nesse modelo, assim como os professores, as organizações sociais também serão avaliadas pelos indicadores de desempenho: "A fonte dos dados para a avaliação do cumprimento das metas serão os relatórios disponíveis no Sistema de Gestão Escolar- Sige/Seduce, no Sistema Administrativo e Pedagógico - Siap/Seduce e no Censo Escolar - MEC e os resultados de avaliações externas Ideb e Idego" (Seduce, 2016, p. 39).

\section{Avaliação externa como fio condutor das reformas neoliberais}

A avaliação em larga escala se consolidou no Brasil como parte importante do monitoramento da educação pública, "propondo-se não somente à aferição da qualidade dos resultados como à indução da qualificação pretendida para os sistemas e instituições de ensino" (Freitas, 2007, p. 1). Desta forma, a avaliação é utilizada como instrumento de pressão em favor de uma educação baseada em conceitos como responsabilização, meritocracia e privatização. Sobre o assunto, Freitas (2012) explica que

esta nova abordagem para as políticas públicas de educação está sendo construída em torno dos conceitos de responsabilização, meritocracia e privatização. Estes constituem um bloco interligado onde a responsabilização pelos resultados (leia-se: aumento da média em testes nacionais e internacionais) é legitimada pela meritocracia (distinções ou sanções fornecidas com base no mérito de ter aumentado ou não as médias) com a finalidade de desenvolver novas formas de privatização do público (o qual é desmoralizado pela meritocracia das médias mais altas), visando a constituição de um "espaço" que se firma progressivamente como "público não estatal" em contraposição ao "público estatal”. (p. 346) 
A avaliação em larga escala desempenha papel essencial neste contexto. Com vistas a introduzir os conceitos supracitados - responsabilização, meritocracia e privatização -, exames de desempenho estão cada vez mais presentes no calendário escolar. Como exemplo pode-se citar a rede municipal do Rio de Janeiro, as escolas se submetem às diversas provas externas de cunho municipal e nacional. Entre elas estão: avaliação diagnóstica, provas bimestrais, Prova Rio, Alfabetiza Rio, Prova Brasil, Provinha Brasil e outras ${ }^{2}$. Além das provas, existem outros instrumentos de consolidação da cultura da prova e do currículo mínimo padronizado, tais como os cadernos pedagógicos, os simulados e o prêmio anual de desempenho.

Muitos estudos sobre avaliação provenientes da academia reforçam a concepção de avaliação formativa, processual e com ênfase qualitativa. Mesmo com divergências acerca do significado dessa, no atual campo de pesquisa sobre avaliação, entende-se que a avaliação deve fazer parte do processo de aprendizagem e não servir somente como mecanismo de classificação e seleção. Na contramão, encontra-se nas políticas educacionais a ideia de avaliação para controle e padronização curricular. Freitas (2012) comenta essa distinção entre os avanços do meio acadêmico e a lógica empresarial na educação, apontando os riscos da influência do segundo grupo:

Os educadores profissionais acompanham este movimento com apreensão, pelo fato de que a educação é um fenômeno social mais amplo e que, do ponto de vista de seus compromissos formativos com a juventude, não pode ter na economia seu único determinante. Ao ser aprisionada na lógica empresarial, a educação perde sua dimensão de um bem público mais amplo, cujos horizontes devem ser um projeto de nação e não apenas a expressão de uma demanda de um dos seus atores, os empresários, por mais importante que estes possam ser. (p. 345)

Apesar disso, no que tange as influências na escrita das políticas de avaliação, a lógica do mercado tem predominado. Esse movimento não é local: a avaliação em larga escala assume características semelhantes em vários países, como é possível ver em Fernandes (2009) que destaca o conjunto de características comuns dos exames públicos nacionais:

1. Os exames são externos, isto é, são preparados e controlados por uma ou mais entidades externas às escolas a que os alunos pertencem; 2. A administração dos exames é normalmente controlada pelo governo ou, no mínimo, por ele supervisionada; 3 . Os exames são elaborados a partir dos conteúdos constantes nos currículos. Em geral, isso significa que se dá mais ênfase ao conhecimento dos conteúdos do que, por exemplo, à sua integração e mobilização para resolver situações problemáticas; 4. As provas de exame são iguais para todos os alunos, administradas segundo procedimentos estandardizados, fora do ambiente normal da sala de aula e realizadas por um grande número de alunos; 5. A maioria dos exames tem várias funções, como certificar, controlar ou selecionar; 6. Normalmente, o conteúdo, os critérios de correção e os resultados dos exames são tornados públicos. (p.118)

2 Em Nazareth (2014), Costa (2011), Calzavara (2011) é possível encontrar estudos sobre a avaliação externa na rede municipal do Rio de Janeiro.

\begin{tabular}{|l|l|l|l|l|l|}
\hline Regae: Rev. Gest. Aval. Educ. & Santa Maria & v. 6 & n. 13 & Set./dez. 2017 & p. 23-36
\end{tabular} 
No geral, a avaliação externa se diferencia de outros tipos de avaliação por objetivar o acompanhamento global de redes de ensino e orientação de políticas públicas. No entanto, é possível observar uma modificação de sua função original, pois as atuais políticas de avaliação externa em conjunto com as políticas de responsabilização criam a "ilusão de que avaliações de larga escala possam avaliar também a escola e os professores" (Freitas, 2009, p. 47). Por isso, é preciso incluir a avaliação em larga escala, praticada pela maioria das instâncias governamentais, no leque das políticas regulatórias que se desenvolveram no seio do projeto político neoliberal. Para Freitas (2009), "as políticas regulatórias querem, em áreas estratégicas, transferir o poder de regulação do Estado para o mercado, dentro de um processo amplo marcado por várias formas de produzir a privatização do público" (p. 54).

Mais do que avaliar redes de ensino para subsidiar a formulação de políticas e ações de melhoria, os indicadores de resultados são ferramentas estratégicas desse discurso. Lima e Gandin (2012) explicam que no Brasil as avaliações foram responsáveis por introduzir a noção de quase-mercado na educação, que é o "processo no qual valores de mercado são adotados nas instituições públicas" (p. 78).

Por tudo isso se afirma que a avaliação tem sido a mola mestra das reformas educacionais. Ou, "em outras palavras, a avaliação está no centro das reformas, no foco das competições que se travam no campo da educação e se referem a disputas mais amplas pela construção de tipos distintos de sociedade" (Dias Sobrinho, 2003, p. 95).

\section{Considerações finais}

É preciso expor os papéis que a avaliação externa tem cumprido em prol do avanço das políticas neoliberais na educação. A partir do que foi pesquisado faz-se possível afirmar que a avaliação externa tem desempenhado as seguintes funções: fortalecer 0 argumento a respeito da crise na educação pública para criar mecanismos de privatização; impor a lógica da performatividade; fortalecer a cultura do exame nas escolas para tentar controlar os conteúdos e tempos escolares.

A respeito da primeira função, os reformadores afirmam que a educação pública sofre uma crise de ineficiência. $O$ argumento que sustenta essa crise favorece a adoção das medidas propostas pelos próprios reformadores. Ravitch (2013) apresenta o discurso dos reformadores nos Estados Unidos da América da seguinte forma:

Nossos alunos não estão aprendendo o suficiente. As escolas públicas são
ruins e estão ficando pior. Estamos perdendo para outros países com os
resultados dos testes mais elevados. Nossas escolas públicas em
decadência ameaçam não só o desempenho da nossa economia, mas a
nossa segurança nacional, a nossa própria sobrevivência como nação.
Essa crise é tão profunda que meias medidas e ajustes não serão
suficientes. Escolas devem ser fechadas e um grande número de
professores demitidos. Quem duvida disso não conhece as dimensões da
crise ou tem interesse em defender o status quo. (p. 3)

Eles sustentam o argumento de que para melhorar a qualidade é preciso melhorar o desempenho, e para melhorar o desempenho é necessário estabelecer metas, entregar a gestão à iniciativa privada, comprar soluções educacionais, fazer mais provas e premiar aqueles que conseguirem alcançar as metas. 
Ravitch (2013), contrariando o discurso dos reformadores, afirma que "a educação pública não está quebrada. Não está falindo ou em declínio. O diagnóstico está errado, e as soluções dos reformadores empresariais estão erradas. Nossas escolas estão em apuros por causa da desigualdade social e segregação racial" (p. 4).

Por trás do argumento da crise, os índices de desempenho assumem a função de justificar a criação de parcerias com empresas privadas e a compra de metodologias de ensino. Não obstante, isso não significa afirmar que a escola pública não precisa melhorar. É necessário valorizar as experiências democráticas e incluir os que estão excluídos. Essas experiências estão enfrentando cada vez mais resistências nas escolas, mas existem. O livro organizado por Apple e Beane (2001) trata de dar visibilidade às escolas democráticas:

As escolas democráticas, como a própria democracia, não surgem por acaso. Resultam de tentativas explícitas de educadores colocarem em prática os acordos e oportunidades que darão vida à democracia. Esses acordos e oportunidades envolvem duas linhas de trabalho. Uma é criar estruturas e processos democráticos por meio dos quais a vida escolar se realize. A outra é criar um currículo que ofereça experiências democráticas aos jovens. (p. 20)

Além disso, é preciso dar atenção às questões estruturais. Os diagnósticos provenientes dos exames não consideram a falta de professores, baixos salários ou más condições de trabalho como importantes para a melhoria da escola pública. Apesar das questões estruturais que os docentes reivindicam, os governos investem milhões no mercado educacional, contratando empresas para criar e aplicar testes, comprando tecnologias e metodologias educacionais padronizadas e repassando a responsabilidade de gerir as escolas.

A segunda função da avaliação externa elencada anteriormente é impor a lógica da performatividade. De acordo com Ball (2006) vivencia-se um movimento de transformação da provisão do serviço público. Os exames criam diagnósticos negativos a respeito da educação pública, enquanto os reformadores, por meio de redes de empreendedores políticos, introduzem a performatividade.

O objetivo de melhorar o desempenho não está necessariamente relacionado ao intento de melhorar a aprendizagem. A política educacional estudada incentiva à melhoria do desempenho e ignora as limitações dos instrumentos de medição. Ao responsabilizar somente os professores pelos resultados e atribuir aos diretores de escola o papel do gerencialismo, a pressão sobre o desempenho é ampliada. Ball (2005) explica que o papel do gerente na educação:

O trabalho do gerente envolve incutir uma atitude e uma cultura nas quais os trabalhadores se sentem responsáveis e, ao mesmo tempo, de certa forma pessoalmente investidos da responsabilidade pelo bem-estar da organização. Nos termos de Bernstein, essas novas pedagogias invisíveis de gerenciamento, realizadas por meio de avaliações, análises e formas de pagamento relacionadas com o desempenho, "ampliam" o que pode ser controlado na esfera administrativa. As estruturas mais frágeis do novo gerencialismo permitem que um leque maior do comportamento e da vida emocional dos trabalhadores se torne público. (apud Bernstein, 1971) (p. 545) 
Assim, é possível observar relativas melhoras em índices de desempenho que não se traduzem necessariamente em aprendizagem e inclusão, muitas vezes estão relacionados à redução curricular e exclusão de alunos considerados ruins nos dias de realização das provas.

Chega-se à terceira função: fortalecer a cultura do exame nas escolas para tentar controlar os conteúdos e tempos escolares. O exame aparece como instrumento que tenta conduzir as práticas escolares no sentido da performatividade e privatização. As políticas de cunho neoliberal para a educação apropriam-se dos exames tradicionais modificando seus sentidos. Sobre isso Barriga (2008) argumenta que

o exame aparece permanentemente como um espaço superdimensionado. Neste espaço se tem o olhar posto. É observado pelos responsáveis pela política educativa, pelos diversos diretores das instituições escolares, pelos pais de famílias, pelos alunos e finalmente pelos próprios docentes. Ainda que cada grupo social possa ter sua representação em relação ao papel que cumpre o exame, todos estes grupos coincidem em termos globais em esperar que através do exame se obtenha um conhecimento "objetivo" sobre o saber de cada estudante. (p. 47)

Essa representação referida pelo autor parte da ideia de que é possível apurar o conhecimento de cada estudante por meio de exames padronizados e aparece como suporte das políticas educacionais. Nesse sentido, é importante ressaltar que essas políticas se sustentam mais nas representações e expectativas dos grupos sociais citados, do que em evidências empíricas e pesquisas com legitimidade no campo acadêmico.

A avaliação em larga escala deixa de ser instrumento de acompanhamento global de redes de ensino e orientador de políticas públicas. Ela passa a ser considerada capaz de avaliar a aprendizagem de alunos e o trabalho de professores.

O exame trata da expressão do conhecimento não é capaz de medir o conhecimento do sujeito em si, ou melhor, "o exame é o instrumento a partir do qual se reconhece administrativamente um conhecimento, mas igualmente reconhece que o exame não indica realmente qual é o saber de um sujeito" (Barriga, 2008, p. 45).

Esses instrumentos de avaliação têm limitações metodológicas e se mostram inadequados nos contextos plurais de um país com as dimensões do Brasil. Ignorar as limitações dos exames padronizados e tentar criar diagnósticos a respeito das aprendizagens é um problema, ainda mais quando várias políticas são criadas em torno desses diagnósticos.

Dessa forma, as ações regulatórias estabelecem pressões para modificar o que significa ser professor. Conquistas históricas dos docentes como o direito à carga horária de planejamento e centro de estudos são desencorajadas. Dentro da perspectiva das atuais políticas o professor tem a função de aplicar o programa elaborado por equipes especializadas, para após isso, serem responsabilizados pelos resultados.

As questões problematizadas neste texto acentuam as desigualdades educacionais e favorecem a criação de formas de exclusão e maneiras de burlar os resultados. Na prática escolar, o professor que acredita na importância da autonomia, no planejamento e 
na pesquisa precisa realizar grandes esforços para conciliar ou resistir às demandas externas, esforços esses que poderiam estar voltados efetivamente para a melhoria do processo educativo.

\section{Referências}

ADRIÃO, Theresa. Escolas charters no EUA: contradições de uma tendência proposta para o Brasil e suas implicações para a oferta da educação pública. Educação e Filosofia Uberlândia, v. 28, 2014, p. 263-282.

AKKARI, Abdeljalil. Internacionalização das políticas educacionais. Petrópolis: Vozes, 2011.

APPLE, Michael. Educando à direita: mercados, padrões, deus e desigualdade. São Paulo: Cortez. 2003.

APPLE, Michael. Para além da lógica do mercado: compreendendo e opondo-se ao neoliberalismo. Rio de Janeiro: DP\&A, 2005.

APPLE, Michael; BEANE, James (orgs.). Escolas democráticas. São Paulo: Cortez, 2001.

BALL, Stephen J. Diretrizes Políticas globais e relações públicas locais em educação. Currículo sem Fronteiras, v. 1, n. 2, 2001, p. 99-116.

BALL, Stephen J. Profissionalismo, gerencialismo e performatividade. Cad. Pesqui., São Paulo, v. 35, n. 126, 2005, p. 539-564.

BALL, Stephen J. Sociologia das políticas educacionais e pesquisa crítico-social: uma revisão pessoal das políticas educacionais e da pesquisa em política educacional. Currículo sem Fronteiras, v. 6, n. 2, 2006, p. 10-32.

BARRIGA, Ángel Días. Uma polêmica em relação ao exame. In: ESTEBAN, Maria. Teresa (org.). Avaliação: uma prática em busca de novos sentidos. Petrópolis: DP, 2008, p. 4366.

MAINARDES, Jefferson. Políticas educacionais: questões e dilemas. São Paulo: Cortez, 2011.

BALL, Stephen J. Novos Estados, nova governança e nova política educacional. In: APPLE, Michael; BALL, Stephen; GANDIN, Luís Armando. Sociologia da educação: análise internacional. Porto Alegre: Penso, 2013, 177-189.

CALZAVARA, Maria Teresa Santos. As práticas avaliativas e os registros de resultados nos anos iniciais do ensino fundamental: um estudo de caso. Rio de Janeiro: Unirio, 2011. 149f. Dissertação (mestrado em Educação). Universidade Federal do Estado do Rio de Janeiro.

COSTA, Maria Helena dos Santos Prazeres. Avaliação: tessituras docentes, caminhos percorridos e desafios que se impõem no cotidiano escolar. Rio de Janeiro: Unirio, 2011. 178f. Dissertação (mestrado em Educação). Universidade Federal do Estado do Rio de Janeiro.

DIAS, Maria Carolina Nogueira. O modelo de escola charter: a experiência de Pernambuco. São Paulo: Instituto Fernand Braudel/Fundação Itaú Social, 2010.

DIAS SOBRINHO, José. Avaliação: políticas educacionais e reformas da educação superior. São Paulo: Cortez, 2003.

FERNANDES, Domingos. Avaliar para aprender: fundamentos, práticas e políticas. São Paulo: Unesp, 2009. 
FREITAS, Dirce Nei. A avaliação da educação básica no Brasil: dimensão normativa, pedagógica e educativa. Campinas: Autores Associados, 2007.

FREITAS, Luiz. Carlos et al. Avaliação educacional: caminhando pela contramão. Petrópolis: Vozes, 2009.

FREITAS, Luiz Carlos. Os reformadores empresariais da educação: a consolidação do neotecnicismo no Brasil. In: FONTOURA, Helena Amaral (org.). Politicas públicas, movimentos sociais: desafios à pós-graduação em educação em suas múltiplas dimensões. Rio de Janeiro: Anped, 2011, p. 72-90.

FREITAS, Luiz Carlos. Os reformadores empresariais da educação: da desmoralização do magistério à destruição do sistema público de educação. Educ. Soc., v. 33, n. 119, 2012, p. 379-404.

HARVEY, David. O neoliberalismo: histórias e implicações. São Paulo: Loyola, 2008.

HOLMES, Dwight. Charter school: uma escola pública que caminha e fala como escola privada: entrevista. [31 de maio, 2016]. São Paulo: Carta Capital. Entrevista concedida a Nora Krawczyk.

LIMA, Iana Gomes; GANDIN, Luís Armando. Entendendo o estado gerencial e sua relação com a educação: algumas ferramentas de análise. Práxis Educativa, Ponta Grossa, v. 7, n. 1, 2012, p. 69-84.

MAINARDES, Jefferson. Abordagem do ciclo de políticas: uma contribuição para a análise de políticas educacionais. Educ. Soc., Campinas, v. 27, n. 94, 2006, p. 47-69.

NAZARETH, Henrique Dias Gomes. Políticas de avaliação externa na prática escolar: efeitos da política educacional em uma sala de aula da rede municipal do Rio de Janeiro. Rio de Janeiro: Unirio, 2014. 122f. Dissertação (mestrado em Educação). Universidade Federal do Estado do Rio de Janeiro.

PERONI, Vera Maria Vidal; CAETANO, Maria Raquel. O público e o privado na educação: projetos em disputa? Retratos da Escola, Brasília, v. 9, n. 17, 2015, p. 337-352.

RAVITCH, Diane. Reign of error: the hoax of the privatization movement and the danger to America's public schools. New York: Alfred A. Knopf, 2013.

SEDUCE. O que você precisa saber sobre as OSs na educação. 2015. Disponível em <http://www.casacivil.go.gov.br/post/ver/206936/o-que-voce-precisa-saber-sobre-as-ossna-educacao>. Acesso em 20 jun. 2016.

SEDUCE. Professores de Stanford visitam governo de Goiás e debatem modelos educacionais. $2016 . \quad$ Disponível em $<$ http://portal.seduc.go.gov.br/SitePages/Mobile/m_noticia.aspx?idNoticia=1553>. Acesso em 20 jun. 2016.

SEDUCE. Aviso de chamamento público n. 1/2016. Goiás, 2016.

Henrique Dias Gomes de Nazareth é pedagogo pela Universidade Federal do Estado do Rio de Janeiro e mestre em Educação pela mesma instituição.

Endereço: Rua Marquês de Jacarepaguá, 240, bloco 1, apto. 204 - 22730-290 - Rio de Janeiro - RJ - Brasil.

E-mail: $\underline{h \text { diasunirio@yahoo.com.br. }}$

Recebido em 3 de abril de 2017.

Aceito em 14 de junho de 2017. 